\title{
Efficacy and safety of triple versus dual antithrombotic therapy in atrial fibrillation and ischemic heart disease: a systematic review and meta-analysis
}

\author{
Wengen Zhu ${ }^{1, *}$, Linjuan Guo ${ }^{1, *}$, Fadi Liu ${ }^{1, *}$, Rong Wan², Yang Shen ${ }^{2}$, Gregory Y.H. \\ Lip $^{3, \#}$ and Kui Hong ${ }^{1,2, \#}$ \\ ${ }^{1}$ Department of Cardiovascular Medicine, the Second Affiliated Hospital of Nanchang University, Nanchang of Jiangxi, China \\ 2 Jiangxi Key Laboratory of Molecular Medicine, Nanchang of Jiangxi, China \\ ${ }^{3}$ University of Birmingham Centre for Cardiovascular Sciences, City Hospital, Birmingham, United Kingdom \\ *These authors share co-first authorship \\ \#These authors share co-senior authorship
}

Correspondence to: Kui Hong, email: hongkui88@163.com

Keywords: atrial fibrillation, ischemic heart disease, triple therapy, dual therapy

Received: April 11, 2017 Accepted: August 26, $2017 \quad$ Published: September 14, 2017

Copyright: Zhu et al. This is an open-access article distributed under the terms of the Creative Commons Attribution License 3.0 (CC BY 3.0), which permits unrestricted use, distribution, and reproduction in any medium, provided the original author and source are credited.

\section{ABSTRACT}

The optimal antithrombotic regimen for patients with atrial fibrillation and ischemic heart disease remains unclear. Therefore, we aimed to compare the efficacy and safety of triple therapy (TT [an anticoagulant and 2 antiplatelet drugs]) with dual therapy (DAPT [2 antiplatelet drugs] or DT [an anticoagulant and a single antiplatelet drug]) in patients with atrial fibrillation and ischemic heart disease. We systematically searched the Cochrane Library, PubMed and Embase databases for all relevant studies up to August 2017. The overall risk estimates were calculated using the random-effects model. A total of 17 observational studies were included. Regarding the efficacy outcomes, no differences were observed between the triple therapy and the dual therapy for all-cause death, cardiovascular death, or thrombotic complications (i.e., acute coronary syndrome, stent thrombosis, thromboembolism/ stroke, and major adverse cardiac and cerebrovascular events). Regarding the safety outcomes, compared with DAPT, TT was associated with increased risks of major bleeding (a relative risk of 1.96 [1.40-2.74]), minor bleeding (1.69 [1.06-2.71]) and overall bleeding (1.80 [1.23-2.64]). Compared wtih DT, TT was associated with a greater risk of major bleeding (1.65 [1.23-2.21]), but rates of minor bleeding (0.99 [0.56-1.77]) and overall bleeding (1.14 [0.76-1.71]) were similar. Overall, TT confers an increased hazard of major bleeding with no thromboembolic protection compared with dual therapy in patients with atrial fibrillation and ischemic heart disease.

\section{INTRODUCTION}

Approximately $20-30 \%$ of atrial fibrillation (AF) patients have coexisting ischemic heart disease (IHD) [1]. Both AF and IHD confer an increased risk of thrombotic complications [2]. Oral anticoagulation (OAC) agents and antiplatelet therapies are beneficial for $\mathrm{AF}$ and IHD patients, respectively [1]. However, selecting the optimal antithrombotic therapy for patients with both AF and IHD remains a challenge, especially for those patients with a high risk of thrombotic complications and bleeding [3]. Recently, 3 antithrombotic strategies are used in the management of patients with IHD and AF: triple therapy (TT [an anticoagulant plus 2 antiplatelet drugs]) and two types of dual therapy (DAPT [2 antiplatelet drugs] or DT [an anticoagulant plus a single antiplatelet drug]). However, the evidence related to these antithrombotic strategies has yielded conflicting results. Some of the studies have reported a decreased risk of thrombotic complications in patients on TT $[4,5]$, whereas other 
studies have demonstrated that the high risk of bleeding associated with TT might outweigh its benefits [6-8]. Dual antithrombotic therapy was found to decrease the risk of major adverse cardiac events in a large study of patients with AF and IHD [9] but did not decrease the risk of coronary death or myocardial infarction (MI) in another study [10]. In this meta-analysis, we aimed to compare the efficacy and safety of TT with those of dual therapies (DAPT or DT) in patients with AF and IHD.

\section{MATERIALS AND METHODS}

We conducted this study according to the metaanalysis of observational studies in epidemiology (MOOSE) guidelines [11] and the Preferred Reporting Items for Systematic Reviews and Meta-Analyses (PRISMA) guidelines [12].

\section{Data sources and searches}

We systematically searched the Cochrane Library, PubMed and Embase databases for studies comparing the efficacy and safety of triple therapy with dual therapy in patients with AF and IHD from database inception until August 2017. To identify studies involving antithrombotic therapies, we used the following keywords: 'dual therapy', 'triple therapy', 'antiplatelet', 'antithrombotic', 'anticoagulant', 'aspirin', 'warfarin', 'vitamin K antagonists', 'acenocoumarol', 'phenprocoumon', 'thienopyridine', 'clopidogrel', 'prasugrel', 'cilostazol' and 'ticlopidine'. To identify studies involving relevant participants, we used the following keywords: 'atrial fibrillation', 'ischemic heart disease', 'coronary heart disease', 'acute coronary syndromes', 'angina pectoris', and 'coronary stenting'. To identify studies involving relevant outcomes, we used the following keywords: 'all-cause mortality', 'cardiovascular mortality', 'mortality', 'death', 'myocardial infarction', 'stroke', 'thromboembolism', 'cerebrovascular accident', 'major adverse cardiac and cerebrovascular events', 'major bleeding', 'minor bleeding', 'bleeding' and 'hemorrhage'. These 3 categories of keywords were combined using the Boolean operator "and". A detailed description of the electronic search strategies is provided in Supplementary Table 1. The references lists of the included studies were also searched, and we did not impose language restrictions on our searches.

\section{Study selection criteria}

Studies were included if they met the following criteria: (a) compared the safety and efficacy of triple therapy with dual therapy; (b) included patients with nonvavular AF and IHD; and (c) reported the efficacy outcomes, including all-cause death, cardiovascular death, acute coronary syndrome (unstable angina and nonfatal
MI), stent thrombosis, thromboembolism(TE)/stroke, and major adverse cardiac and cerebral events (MACCEs) or reported on the safety outcomes, including major bleeding, minor bleeding and overall bleeding. The definitions of outcomes adopted by the original studies are summarized in Supplementary Table 2. To avoid underpowered data, we excluded studies with follow-up durations of less than 1 year. In cases of duplicate publications, we included the publication with the longest follow-up duration or the largest number of study participants. Studies with insufficient data were also excluded (e.g., certain publication types with no statistics [e.g., reviews, letters, and case reports], and clinical studies that did not report the risk estimates or relevant outcomes).

\section{Patient involvement}

No patients were involved in setting the research question, in the outcome measures, in the design, or in the implementation of the study. No patients were asked for advice on the interpretation or writing up of the results. There are no plans to disseminate the results of the research to study participants or to the relevant patient community.

\section{Data extraction and quality assessment}

Three independent reviewers (W.G.Z., L.J.G. and F.D.L.) screened all of the identified titles and/or abstracts and then retrieved the full-texts of the shortlisted studies. Disagreements were resolved via discussion with a fourth reviewer (K.H.). The data were extracted from each included study as follows: the first author, year of publication, duration of follow-up, ages at baseline, sample size, outcomes, proportion of female participants, number of participants receiving each treatment regimen, data source, antithrombotic medications, and relative risks [RRs] with the $95 \%$ confidence intervals [CIs]. If both unadjusted and adjusted RRs were available in one study, the most adjusted RRs were extracted. Three reviewers (W.G.Z., L.J.G. and F.D.L.) independently assessed the included studies' qualities using the Newcastle-Ottawa quality assessment scale (NOS) [13]. NOS scores $<6$ indicated low quality studies, and scores $\geq 6$ indicated moderate-high quality studies.

\section{Statistical analyses}

We performed all of the statistical analyses using the Review Manager 5.3 software (Cochrane Collaboration, Copenhagen, Denmark). The efficacy and safety outcomes were defined dichotomously, and we compared their occurrence risks between triple therapy and dual therapy. The statistical analyses were performed as previously described [14]. In brief, the RRs were used as the common risk estimates, and we calculated the natural logarithm 
of the RR $(\log [R R])$ and its standard error $\left(\mathrm{SE}_{\log [\mathrm{RR}]}\right)$ for each study. In the consistency test, the heterogeneity was assessed with the $I^{2}$ statistical test for which $I^{2}$ values $<25 \%$, $25-50 \%$, and $>75 \%$ were considered indicative of low, moderate, and high levels of heterogeneity, respectively. Owing to the heterogeneity inherent (both clinically and methodologically) to the included studies, the $\log [\mathrm{RR}]$ and $\mathrm{SE}_{\log [\mathrm{RR}]}$ values were pooled with the random-effects model, which is a more conservative method than the fixedeffects model [15]. We determined the degree of possible publication bias by inspecting funnel plots. To evaluate the influence of individual studies on the pooled data, we conducted sensitivity analyses by removing the included studies one by one. A $P$-value less than 0.05 indicated statistical significance.

\section{RESULTS}

\section{Study selection}

Figure 1 presents a flow chart of the study selection process. We identified 860 relevant studies (28 through the Cochrane Library, 482 through PubMed, and 350 through Embase). No additional studies were identified through manual searches. A total of 816 studies were excluded based on their titles or abstracts. The remaining 44 studies were eligible for detailed full-text evaluations. Twenty-seven of those studies were excluded for the following reasons: (1) they were studies that included IHD patients both with and without AF $(n=12)$ [16-27] or studies including AF patients with and without IHD ( $n$ $=1)$ [28]; and (2) the studies had insufficient data $(n=9$; 5 studies did not compare the outcomes of triple therapy with those of dual therapy [29-33], 2 studies did not report the outcomes of interest $[34,35]$, and 2 studies did not report the risk estimates $[36,37])$, duplicate data $(n=3)$ [38-40] or follow up data of less than 1 year $(n=2)$ $[41,42]$. Ultimately, 17 studies [4-10, 43-52] (8 prospective and 9 retrospective studies) were included in this meta-analysis. The baseline characteristics of these included studies are presented in Supplementary Table 4.

\section{Quality assessment and publication bias}

As illustrated in Supplementary Table 3, all of the included studies had an NOS score $\geq 6$ (graded as

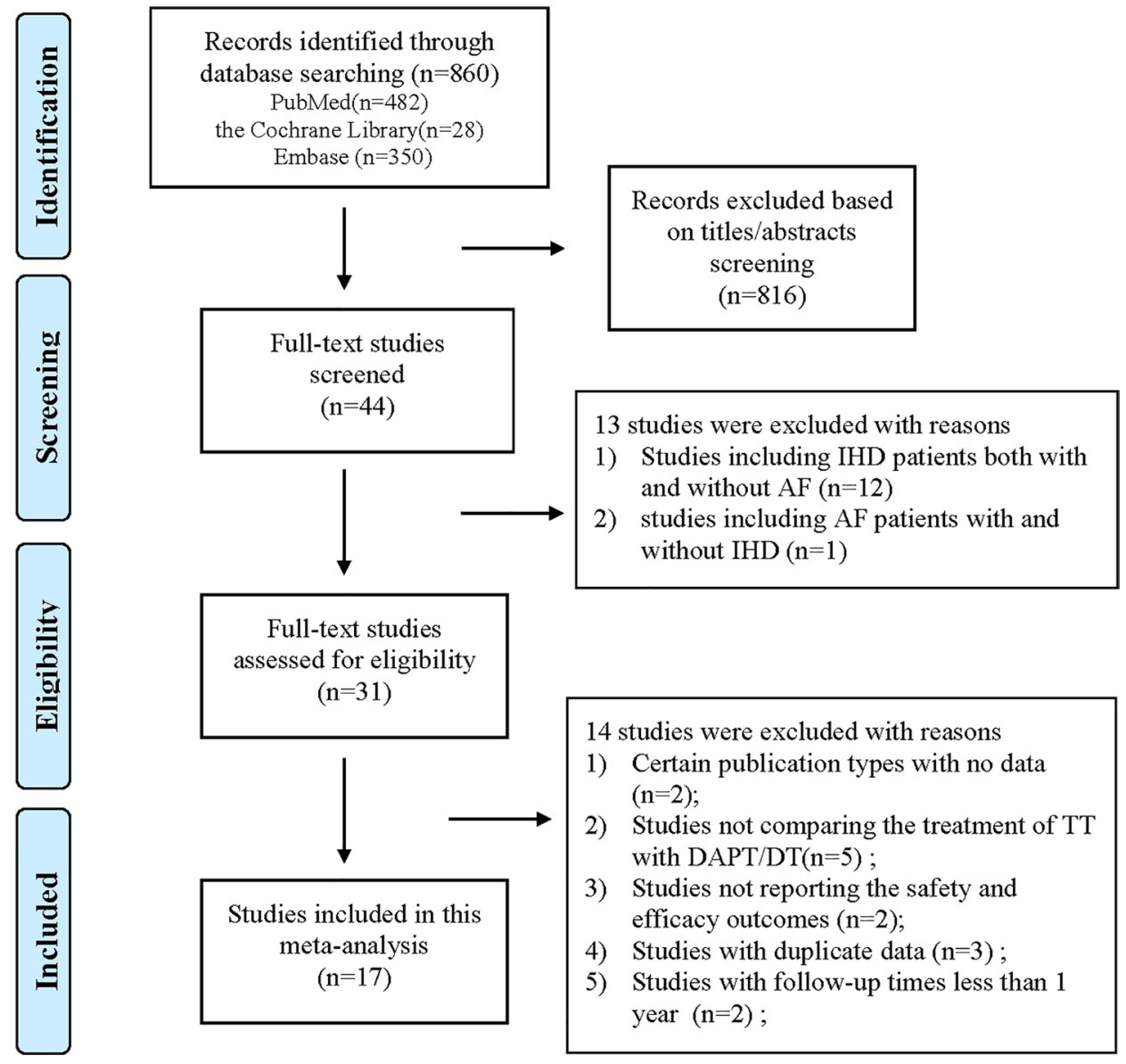

Figure 1: Flow chart of the study selection process for this meta-analysis. Abbreviations: IHD = ischemic heart disease; $A F$ $=$ atrial fibrillation; $\mathrm{TT}=$ triple therapy (an oral anticoagulant plus 2 antiplatelet drugs); DAPT $=$ dual therapy $(2$ antiplatelet drugs); DT $=$ dual therapy (an oral anticoagulant plus one antiplatelet drug). 
moderate to high quality). As shown in Supplementary Figure 1, visual inspection of the funnel plots of the efficacy and safety outcomes between the triple therapy and dual therapy indicated no major publication bias.

\section{Efficacy outcomes of the triple versus the dual therapies}

When comparing the efficacy outcomes between the triple therapy and the dual therapy, we focused on the outcomes of all-cause death, cardiovascular death and thrombotic complications (acute coronary syndrome, stent thrombosis, TE/stroke and MACCEs). As presented in Figures 2 and 3, the consistency test indicated a low to moderate degree of heterogeneity, i.e., the $I^{2}$ values ranged from $0 \%$ to $49 \%$.

\section{Association with death}

For all-cause death, the random-effects model analysis indicated no difference in the risks between TT and DAPT $(\mathrm{RR}=0.84$; 95\% CI: 0.66-1.08; $P=0.17$; Figure 2) or between TT and DT $(\mathrm{RR}=1.21 ; 95 \% \mathrm{CI}$ : $0.78-1.88 ; P$ $=0.39$; Figure 3 ). For cardiovascular death, the risks were comparable between TT and DAPT $(\mathrm{RR}=0.85 ; 95 \% \mathrm{CI}$ : $0.52-1.41 ; P=0.54$; Figure 2$)$ and between TT and DT (RR $=1.43$; 95\% CI: 0.94-2.18; $P=0.09$; Figure 3).

\section{Association with thrombotic complications}

The ACS/MI risks were comparable between TT and DAPT $(\mathrm{RR}=0.87 ; 95 \% \mathrm{CI}: 0.57-1.33 ; P=0.52$; Figure 2) and between TT and DT $(\mathrm{RR}=0.92 ; 95 \% \mathrm{CI}$ : $0.46-1.87 ; P=0.83$; Figure 3 ). For stent thrombosis, the pooled analysis indicated no difference in the risks between TT and DAPT $(\mathrm{RR}=0.71$; 95\% CI: 0.29-1.71; $P=0.44$; Figure 2) or between TT and DT $(\mathrm{RR}=0.57$; 95\% CI: $0.18-1.86 ; P=0.35$; Figure 3 ). For the outcome of TE/stroke, there was also no difference between TT and DAPT $(\mathrm{RR}=0.74 ; 95 \% \mathrm{CI}: 0.49-1.13 ; P=0.17$; Figure 2) or between TT and DT $(\mathrm{RR}=1.55 ; 95 \% \mathrm{CI}$ : 0.89-2.72; $P=0.12$; Figure 3 ). Finally, the risk of MACCEs was comparable between TT and DAPT $(\mathrm{RR}=0.89$; 95\% CI: $0.76-1.05 ; P=0.17$; Figure 2$)$ and between TT and DT $(\mathrm{RR}=1.14$; 95\% CI: 0.75-1.73; $P=0.55$; Figure 3$)$.

\section{Sensitivity analysis}

None of the RR values changed substantially following the removal of the included studies one by one. For TT versus DAPT, the results were stable when we reperformed these analyses with fixed effects models.

\section{Safety outcomes of the triple versus the dual therapies}

Major bleeding, minor bleeding, and overall bleeding were regarded as the safety outcomes. The consistency test indicated a moderate to high heterogeneity for TT versus DAPT ( $I^{2}$ ranging from $58 \%$ to $72 \%$ ) and a low heterogeneity for TT versus DT ( $I^{2}$ ranging from $0 \%$ to $11 \%$ ).

\section{Association with bleeding}

As illustrated in Figure 4, compared with DAPT, TT was associated with increased risks of major bleeding $(\mathrm{RR}=1.96 ; 95 \% \mathrm{CI}: 1.40-2.74 ; P<0.0001)$, minor bleeding $(\mathrm{RR}=1.69 ; 95 \% \mathrm{CI}: 1.06-2.71 ; P=0.03)$, and overall bleeding $(\mathrm{RR}=1.80 ; 95 \% \mathrm{CI}$ : 1.23-2.64; $P=0.03)$. As presented in Figure 5, compared with DT, TT was associated with an increased risk of major bleeding $(\mathrm{RR}=1.65 ; 95 \% \mathrm{CI}: 1.23-2.21 ; P=0.0008)$ but with similar rates of minor bleeding $(\mathrm{RR}=0.99 ; 95 \% \mathrm{CI}$ : $0.56-1.77 ; P=0.97)$ and overall bleeding $(\mathrm{RR}=1.14$; 95\% CI: $0.76-1.71 ; P=0.51)$.

\section{Sensitivity analysis}

Most of the RR values did not change substantially following the removal of the included studies one by one. Additionally, the results were stable following a change from the random to the fixed effects models. Notably, when comparing major bleeding associated with TT versus DT, the study of Lamberts et al. [48] had a weight of $58.3 \%$ in the pooled analysis. After excluding this study, TT was still associated with an increased, although not significant, risk of major bleeding compared with DT $(\mathrm{RR}=1.33 ; 95 \% \mathrm{CI}: 0.85-2.09 ; P=0.21)$.

\section{DISCUSSION}

Treatment for AF-related thromboembolism benefits from OAC, whereas antiplatelet therapy is useful for IHDinduced arterial thrombosis. Thus, combination treatment involving $\mathrm{OAC}$ and antiplatelet therapy is presumed to prevent the thrombotic complications in patients with AF and IHD [53]. Balancing the risks of bleeding and thrombotic complications is a key consideration that should be carefully considered by clinicians so they can make optimal antithrombotic therapy decisions [54]. To date, the optimal antithrombotic therapy regimen for AF and IHD patients remains a subject of debate. To the best of our knowledge, our meta-analysis is the first to compare the efficacies and safeties of 3 antithrombotic therapy strategies in a large number of patients with AF and IHD. Our principal findings were as follows: (i) compared with DAPT, TT was associated with increased risks of major bleeding, minor bleeding and overall bleeding but did not reduce the risk of death or thrombotic complications (i.e., acute coronary syndrome, stent thrombosis, TE/stroke and MACCEs); and (ii) compared with DT, TT was associated with an increased risk of major bleeding but was not different in terms of the risks of minor bleeding, overall bleeding, death or thrombotic complications. Our results were stable and reliable in the sensitivity analysis. 


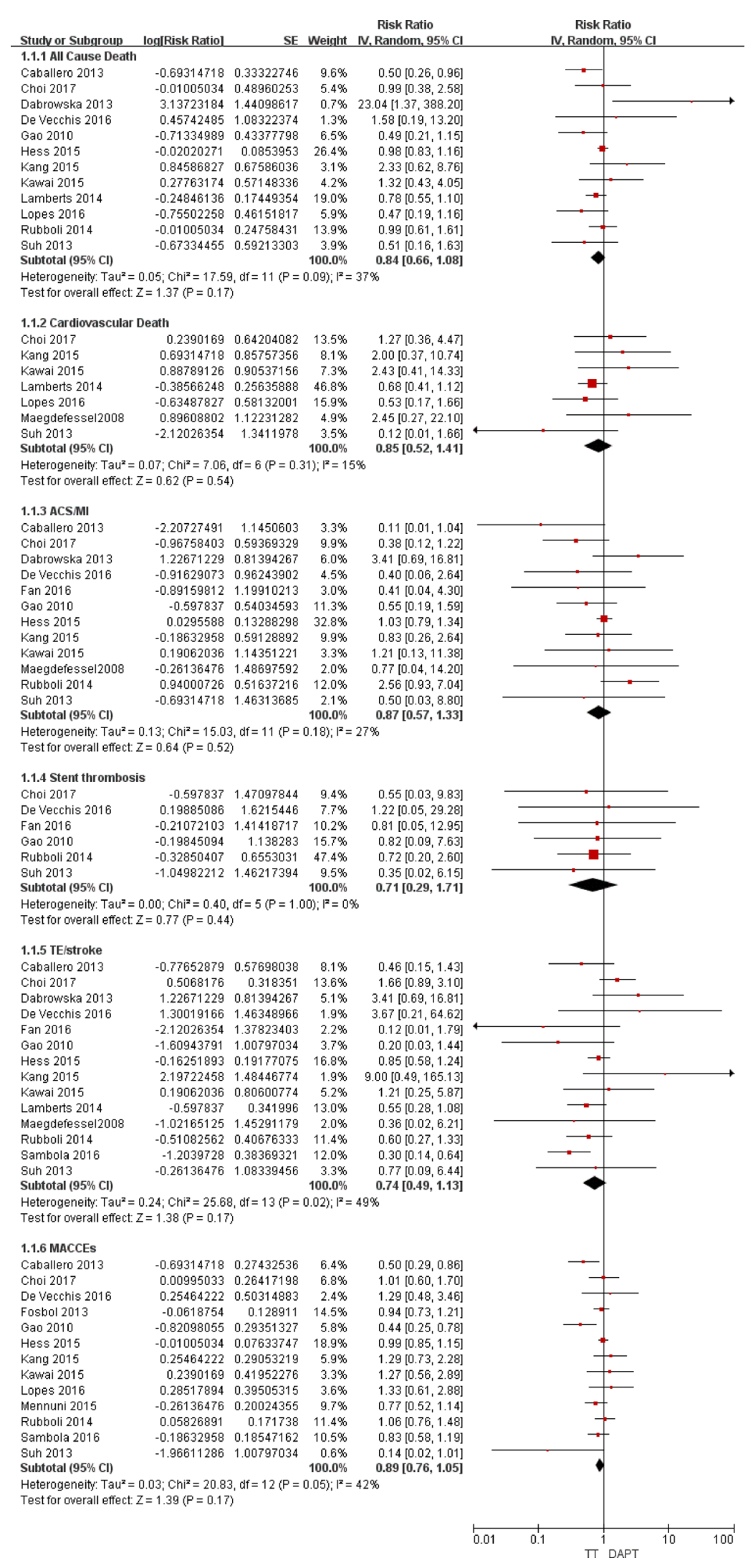

Figure 2: Forest plot for the comparative analysis of the efficacies of TT and DAPT in patients with AF and IHD. Abbreviations: $\mathrm{IHD}=$ ischemic heart disease; $\mathrm{AF}=$ atrial fibrillation; $\mathrm{TT}=$ triple therapy (an oral anticoagulant plus 2 antiplatelet drugs); $\mathrm{DAPT}=$ dual therapy $(2$ antiplatelet drugs); $\mathrm{MI}=$ myocardial infarction; $\mathrm{ACS}=$ acute coronary syndrome; $\mathrm{TE}=$ thromboembolism; MACCEs = major adverse cardiac and cerebrovascular events; $\mathrm{SE}=$ standard error; $\mathrm{CI}=$ confidence interval; $\mathrm{IV}=$ inverse of the variance. 


\section{TT versus DAPT}

A previous meta-analysis indicated that TT has no additional beneficial effects in patients undergoing percutaneous coronary interventions (PCIs) compared with DAPT [55]. Another meta-analysis consisting of 14 observational studies also noted that compared with DAPT, TT did not reduce the risk of thrombotic events but did increase the risk of major bleeding in acute coronary syndrome patients [56]. Among patients with AF and IHD, our current study demonstrated similar findings in that TT was equivalent to DAPT in terms of death and thrombotic complications but increased the bleeding events. The increased bleeding risk associated with both $\mathrm{OAC}$ agents and antiplatelet agents may be related to the duration of therapy. A study performed by Olson et al. reported that the prevalence of major bleeding associated with TT is $2.6-4.6 \%$ at 30 days after treatment initiation but increases to $7.4-10.3 \%$ at 12 months [57]. Even shortterm TT treatment, which has no safe therapeutic window in stented patients with $\mathrm{AF}$, is hazardous with respect to the risk of bleeding [38]. Although the duration of TT may influence the bleeding rates, we could not perform the subgroup analysis because our included studies had different durations of follow-up that varied from 12 months to 74.4 months.

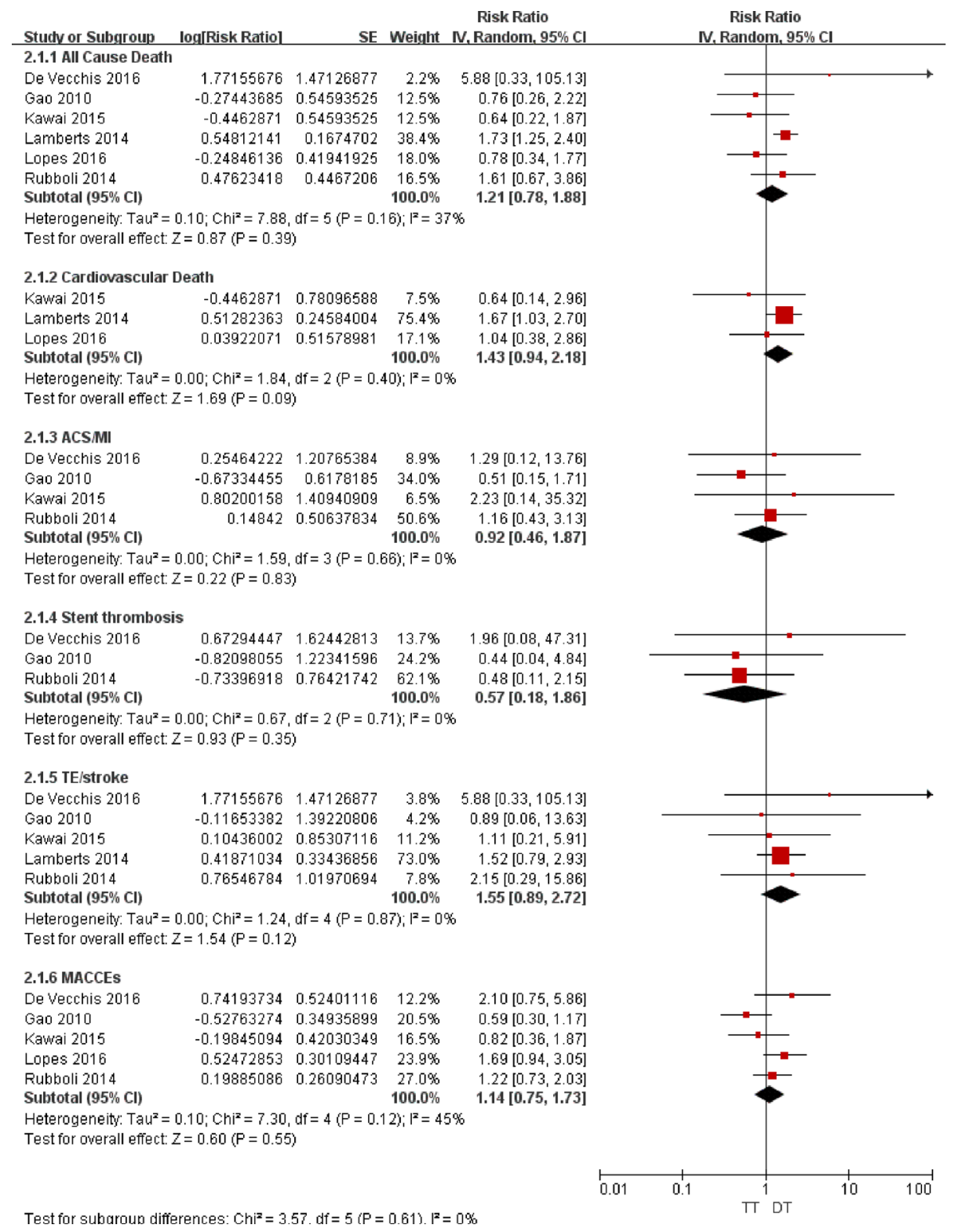

Figure 3: Forest plot for the comparative analysis of the efficacies of TT and DT in patients with AF and IHD. Abbreviations: $\mathrm{IHD}=$ ischemic heart disease; $\mathrm{AF}=$ atrial fibrillation; $\mathrm{TT}=$ triple therapy (an oral anticoagulant plus 2 antiplatelet drugs); $\mathrm{DT}=$ dual therapy (an oral anticoagulant plus one antiplatelet drug); $\mathrm{MI}=$ myocardial infarction; $\mathrm{ACS}=$ acute coronary syndrome; TE $=$ thromboembolism; MACCEs $=$ major adverse cardiac and cerebrovascular events; $\mathrm{SE}=$ standard error; $\mathrm{CI}=$ confidence interval; $\mathrm{IV}=$ inverse of the variance. 
Various clinical risk factors could be associated with an increased risk of bleeding, such as advanced age, uncontrolled hypertension, ischemic heart disease, cerebrovascular disease, labile international normalized ratio (INR) control and previous bleeding episodes [58]. Bleeding risk schemes such as the HAS-BLED (Hypertension, Abnormal renal/liver function, Stroke, Bleeding history or predisposition, Labile INR, Elderly [older than 65 years of age], Drugs/alcohol concomitantly) score contain almost all of the relevant modifiable and partially non-modifiable clinical risk factors for bleeding. The HAS-BLED score should be appropriately used to evaluate patients who are potentially at risk for bleeding and to address the potentially reversible bleeding risk factors. The HAS-BLED score has also been validated in patients with acute coronary syndrome undergoing PCI and in patients on TT [25]. When clinicians tightly control the INR such that it is maintained between 2.0 and 2.5 in AF and IHD patients, TT may be associated with fewer bleeding complications [59].

\section{TT versus DT}

In patients undergoing PCI, there were no differences in the risk of MI, stroke or stent thrombosis between TT and DT [60]. However, this study did not focus on patients with AF. A recently published meta-analysis involving 7,276 anticoagulated patients undergoing PCI indicated that TT confers a higher risk of major bleeding but confers no differences in death, major adverse cardiac events, MI, stent thrombosis, or the thromboembolic event rate compared with DT [61]. Indeed, the WOEST (What is the optimal antiplatelet and anticoagulant therapy in patients with oral anticoagulation and coronary stenting) trial of

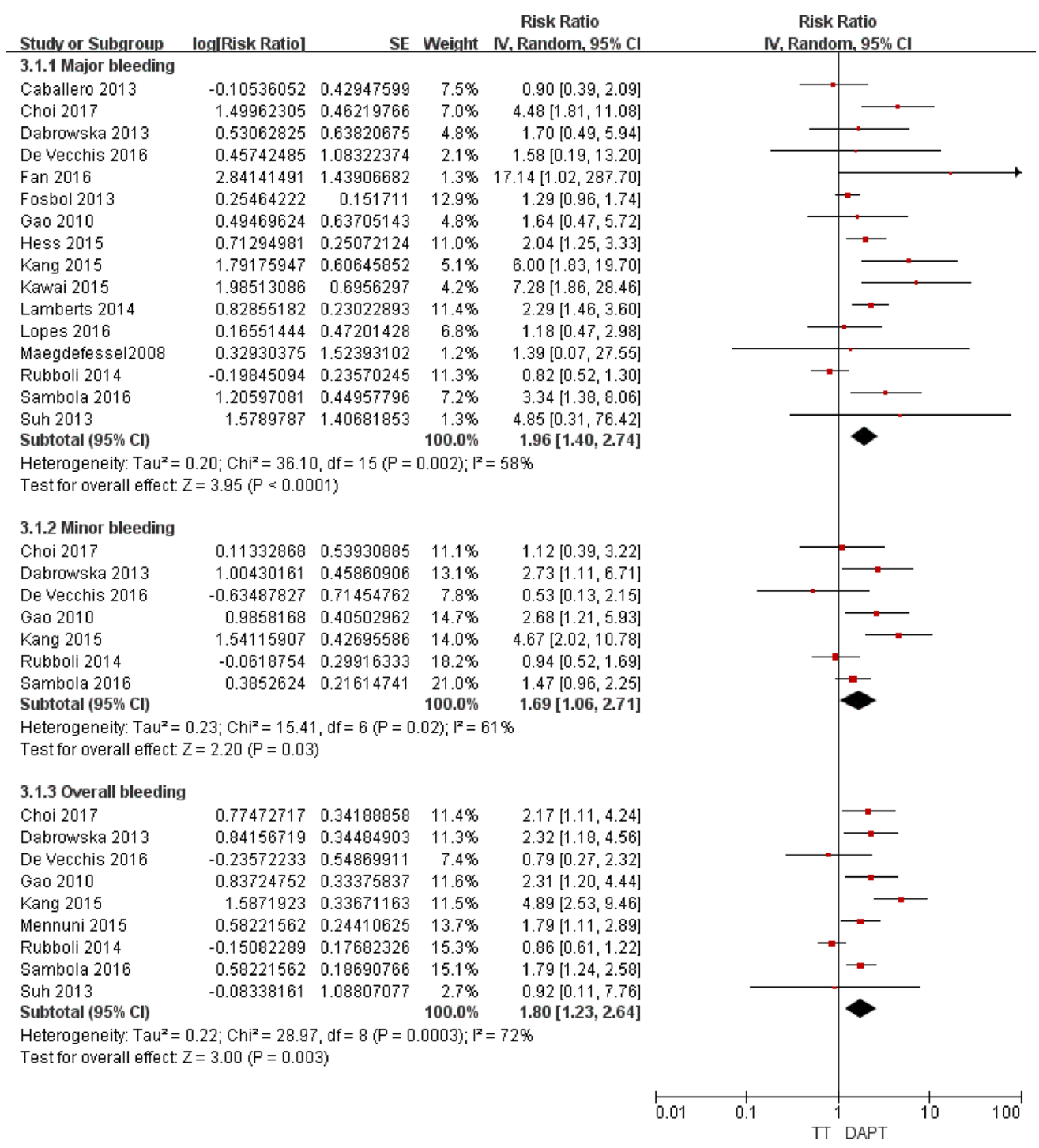

Figure 4: Forest plot for the comparative analysis of the safeties of TT and DAPT in patients with AF and IHD. Abbreviations: IHD = ischemic heart disease; $\mathrm{AF}=$ atrial fibrillation; TT = triple therapy (an oral anticoagulant plus 2 antiplatelet drugs); $\mathrm{DAPT}=$ dual therapy (2 antiplatelet drugs); $\mathrm{MI}=$ myocardial infarction; MACCEs = major adverse cardiac and cerebrovascular events; SE $=$ standard error; $\mathrm{CI}=$ confidence interval; $\mathrm{IV}=$ inverse of the variance. 
stented patients receiving anticoagulants found that TT resulted in no differences in composite thromboembolic endpoints (including MI, stroke, stent thrombosis and target-vessel revascularization) but increased the bleeding risk compared to OAC plus clopidogrel [17]. Because these studies included both AF and non-AF anticoagulated patients (e.g., patients with mechanical valves, dilated cardiomyopathy, venous thromboembolisms, and apical aneurysms), our meta-analysis first involved only the AF patients with IHD for further analysis. In accordance with the previous findings by Lamberts et al. [38, 39, 48], we demonstrated that TT increased the risk of serious bleeding while eliciting no difference in thrombotic complications. Notably, the increased bleeding risk associated with TT was for minor bleeding in the WOEST trial but for major bleeding in our meta-analysis. Our pooled data from 3 included studies indicated no difference in the risk of minor bleeding between TT and DT, which contrasts with the WOEST trial. Clinicians should not underestimate the effects of minor bleeding because superficial or "nuisance" bleeding may cause the discontinuation of antiplatelet therapy and subsequently result in thrombotic complications [62]. Given the limited number of studies included in our minor bleeding analysis, further studies are warranted to confirm our findings. In contrast to our findings, the WOEST trial indicated a lower risk of death in patients on OAC plus clopidogrel. In the study of
Lamberts et al. [38], OAC plus clopidogrel was associated with a lower risk of death, whereas OAC plus aspirin was associated with a higher death rate than TT. In our metaanalysis, DT was defined as an oral anticoagulant plus one antiplatelet drug (either clopidogrel or aspirin). Thus, the association might have been attenuated such that TT had a risk of death comparable to that of DT. The discrepancies in patient selection and the antithrombotic regimens of DT between the WOEST trial and our meta-analysis might potentially provide the explanations for differing findings, and further studies are warranted to address this issue.

\section{Implications and further research}

For patients with AF and IHD, the 2014 European revascularization guidelines recommend TT as a priority selection (class IIa, level of evidence $\mathrm{C}$ ) and recommend DT as an alternative to TT (class IIb, level of evidence B) [63]. The 2016 European Society of Cardiology guidelines recommend DT as an alternative to initial TT to balance the risk of thrombotic complications with the risk of bleeding [64]. However, these guidelines consist mainly of expert consensus opinions that are based mostly on observational studies with small sample sizes. As more attention has been devoted to bleeding events, clinicians and researchers have recommended balancing the risks of thrombotic and bleeding complications when

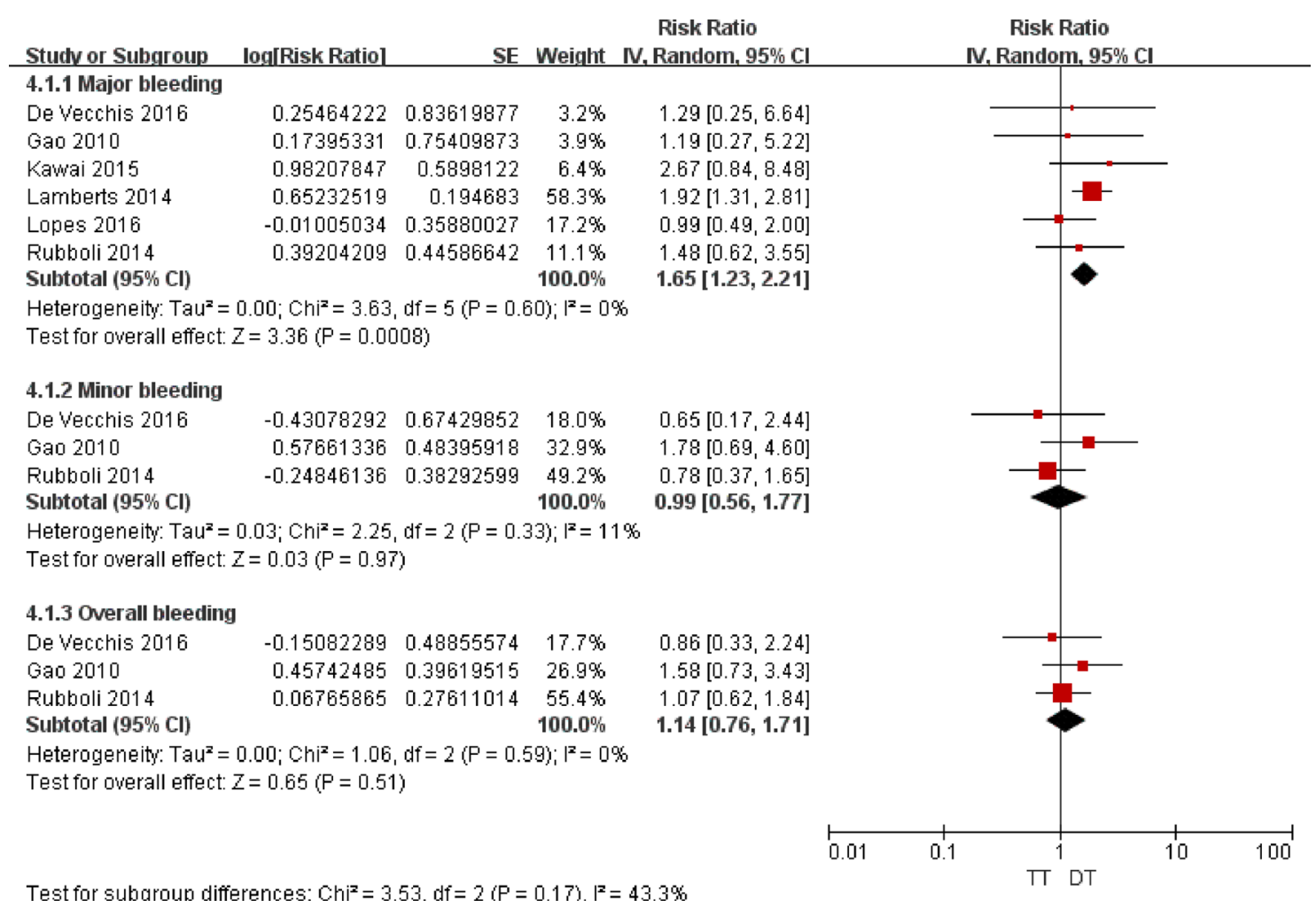

Figure 5: Forest plot for the comparative analysis of the safeties of TT and DT in patients with AF and IHD. Abbreviations: $\mathrm{IHD}=$ ischemic heart disease; $\mathrm{AF}=$ atrial fibrillation; $\mathrm{TT}=$ triple therapy (an oral anticoagulant plus 2 antiplatelet drugs); DT = dual therapy (an oral anticoagulant plus one antiplatelet drug); $\mathrm{MI}=$ myocardial infarction; MACCEs = major adverse cardiac and cerebrovascular events; $\mathrm{SE}=$ standard error; $\mathrm{CI}=$ confidence interval; $\mathrm{IV}=$ inverse of the variance. 
choosing antithrombotic strategies [54] Because there are distinct effects associated with different antithrombotic therapies in patients with AF and IHD, the antithrombotic therapy decisions require a careful, individualized assessment of the benefits and risks of therapy for each patient. Compared with dual therapy, triple therapy yielded more bleeding events but with no difference in the incidence of thrombotic complications. Thus, the benefit of triple therapy seems to have diminished, and the initiation of triple therapy may be unnecessary. Clinicians should be aware of the hazard of adding additional oral anticoagulants to dual therapy.

Although our results provide further support for the previous evidence suggesting that triple therapy is associated with increased risks of major bleeding and with no thromboembolic protection compared with dual therapy, our findings cannot change the approach to current practice. Recently, non-vitamin $\mathrm{K}$ antagonist oral anticoagulants (NOACs) have been increasingly used in current practice. NOACs (e.g., dabigatran and rivaroxaban) [65] are associated with lower risks of TE/ stroke and intracranial hemorrhage compared to vitamin $\mathrm{K}$ antagonists among patients with nonvavular AF. In the ATLAS ACS 2-TIMI 51 (Anti-Xa Therapy to Lower Cardiovascular Events in Addition to Standard Therapy in Subjects with Acute Coronary Syndrome-Thrombolysis in Myocardial Infarction 51) study, the highest dose of rivaroxaban reduced the risk of ischemic events but resulted in excessive bleeding events, whereas very-lowdose rivaroxaban did not increase fatal bleeding events among patients with acute coronary syndrome [66]. Based on these findings, whether the addition of NOACs to dual therapy could be a safer choice is a subject of continued interest. Indeed, in the recent open-label, randomized, controlled, multicenter study (PIONEER AF-PCI) involving 2124 stented patients with $\mathrm{AF}$, both low-dose rivaroxaban (15 mg once daily) plus a P2Y12 inhibitor and very-low-dose rivaroxaban (2.5 $\mathrm{mg}$ twice daily) plus DAPT were associated with lower bleeding risks than standard triple therapy with a vitamin $\mathrm{K}$ antagonist plus DAPT. The risks of cardiovascular death, MI, and stroke were similar in these 3 groups [67]. Additionally, subsequent randomized trials, such as the RT-AF (Rivaroxaban and Ticagrelor in Atrial Fibrillation) [68], REDUAL-PCI (Randomized Evaluation of Dual Therapy with Dabigatran versus Triple Therapy Strategy with Warfarin in Patients with nonvalvular atrial fibrillation that have undergone percutaneous coronary intervention with Stenting) [69] and AUGUSTUS (Apixaban in NonValvular Atrial Fibrillation with a Recent Acute Coronary Syndrome or Undergoing Percutaneous Coronary Intervention) [70] will provide more data regarding the antithrombotic management of patients with IHD and AF. The inclusion of data on NOACs, when available, would improve future antithrombotic management.

\section{Limitations}

Several potential limitations of this meta-analysis should be carefully addressed. First, the clinical heterogeneity inherent among the included studies could not be resolved. Some of our included studies did not report the outcomes of ischemic stroke and hemorrhagic stroke separately. This aspect is an important issue given the different underlying pathophysiology and differing effects of antithrombotic therapy on these stroke risks. Additionally, almost all the included studies failed to differentiate stented patients undergoing PCI from patients with stable coronary artery disease. Moreover, the definitions employed for outcomes varied among the included studies. Second, the quality of INR control in the warfarin-treated patients was closely related to the outcomes; however, we were unable to conduct this analysis because of a lack of sufficient INR control data. Third, we could not perform a subgroup analysis based on the duration of therapy due to the various follow-up times. Future studies should address this issue because all of the endpoints increase over time due to the duration of treatment. Fourth, the potential role of NOACs as the sole OAC strategy has not been directly assessed due to limited data. In terms of clinical applicability, further studies should be undertaken to investigate the efficacy and safety of NOACs combined with antiplatelet drugs.

\section{CONCLUSIONS}

In summary, our analysis suggests that triple therapy confers an increased hazard of major bleeding with no extra thromboembolic protection compared with dual therapy among patients with AF and IHD. Further randomized studies of NOACs are warranted and may improve antithrombotic management.

\section{Authors contributions}

K.H. was responsible for the entire project and revised the draft of the manuscript. W.G.Z., L.J.G. and F.D.L. performed the systematic literature review, constructed the database and analysed the data. W.G.Z., L.J.G. and F.D.L. drafted the first version of the manuscript. All authors took part in the interpretation of the results and in the preparation of the final version of the manuscript.

\section{ACKNOWLEDGMENTS}

The authors thank Peng Huang, a statistician (School of Public Health, Nanchang University, Jiangxi, China), for the analysis and interpretation of the data and revision of the article. 


\section{CONFLICTS OF INTEREST}

None declared.

\section{FUNDING}

This study was funded by the National Natural Science Foundation of China [No 81370288; 8153000545; 81530013] and the National Basic Research Program of China [973 Program: 2013CB531103].

\section{REFERENCES}

1. Camm AJ, Lip GY, De Caterina R, Savelieva I, Atar D, Hohnloser SH, Hindricks G, Kirchhof P. 2012 focused update of the ESC Guidelines for the management of atrial fibrillation: an update of the 2010 ESC Guidelines for the management of atrial fibrillation--developed with the special contribution of the European Heart Rhythm Association. Europace. 2012; 14:1385-1413.

2. Konstantino Y, Zelnik YD, Friger MD, Sahar G, Knyazer B, Amit G. Postoperative Atrial Fibrillation Following Coronary Artery Bypass Graft Surgery Predicts Long-Term Atrial Fibrillation and Stroke. Isr Med Assoc J. 2016; 18:744-748.

3. Bang CN, Gislason GH, Greve AM, Bang CA, Lilja A, Torp-Pedersen C, Andersen PK, Kober L, Devereux RB, Wachtell K. New-onset atrial fibrillation is associated with cardiovascular events leading to death in a first time myocardial infarction population of 89,703 patients with long-term follow-up: a nationwide study. J Am Heart Assoc. 2014; 3:e382.

4. Gao F, Zhou YJ, Wang ZJ, Shen H, Liu XL, Nie B, Yan ZX, Yang SW, Jia DA, Yu M. Comparison of Different Antithrombotic Regimens for Patients With Atrial Fibrillation Undergoing Drug-Eluting Stent Implantation. Circ J. 2010; 74:701-708.

5. Caballero L, Ruiz-Nodar JM, Marin F, Roldan V, Hurtado JA, Valencia J, Manzano-Fernandez S, Sogorb F, Valdes M, Lip GY. Oral anticoagulation improves the prognosis of octogenarian patients with atrial fibrillation undergoing percutaneous coronary intervention and stenting. Age Ageing. 2013; 42:70-75.

6. Kang DO, Yu CW, Kim HD, Cho JY, Joo HJ, Choi RK, Park JS, Lee HJ, Kim JS, Park JH, Hong SJ, Lim D. Triple antithrombotic therapy versus dual antiplatelet therapy in patients with atrial fibrillation undergoing drug-eluting stent implantation. Coronary Artery Dis. 2015; 26:372-380.

7. Kawai H, Watanabe E, Yamamoto M, Harigaya H, Sano K, Takatsu H, Muramatsu T, Naruse H, Sobue Y, Motoyama S, Sarai M, Takahashi H, Arakawa T, et al. Major bleeding complications related to combined antithrombotic therapy in atrial fibrillation patients 12 months after coronary artery stenting. J Cardiol. 2015; 65:197-202.

8. Sambola A, Mutuberria M, Garcia DBB, Alonso A, Barrabes JA, Alfonso F, Bueno H, Cequier A, Zueco
J, Rodriguez-Leor O, Bosch E, Tornos P, GarciaDorado D. Effects of Triple Therapy in Patients With Non-Valvular Atrial Fibrillation Undergoing Percutaneous Coronary Intervention Regarding Thromboembolic Risk Stratification. Circ J. 2016; 80:354-362.

9. Lopes RD, Rao M, Simon DN, Thomas L, Ansell J, Fonarow GC, Gersh BJ, Go AS, Hylek EM, Kowey P, Piccini JP, Singer DE, Chang P, et al. Triple vs Dual Antithrombotic Therapy in Patients with Atrial Fibrillation and Coronary Artery Disease. The American Journal of Medicine. 2016; 129:592-599.

10. Rubboli A, Schlitt A, Kiviniemi T, Biancari F, Karjalainen PP, Valencia J, Laine M, Kirchhof P, Niemela M, Vikman S, Lip GY, Airaksinen KE. One-year outcome of patients with atrial fibrillation undergoing coronary artery stenting: an analysis of the AFCAS registry. Clin Cardiol. 2014; 37:357-364.

11. Stroup DF, Berlin JA, Morton SC, Olkin I, Williamson GD, Rennie D, Moher D, Becker BJ, Sipe TA, Thacker SB. Meta-analysis of observational studies in epidemiology: a proposal for reporting. Meta-analysis Of Observational Studies in Epidemiology (MOOSE) group. Jama. 2000; 283:2008-2012.

12. Moher D, Liberati A, Tetzlaff J, Altman DG. Preferred reporting items for systematic reviews and meta-analyses: the PRISMA statement. Int J Surg. 2010; 8:336-341.

13. Wells GA, Shea B, O Connell D, Peterson J, Welch V, Losos M, Tugwell P. The Newcastle Ottawa Scale (NOS) for assessing the quality if nonrandomized studies in metaanalyses. 2014. Available at: http://www.ohri.ca/programs/ clinical_epidemiology/oxford.asp. Accessed November 20, 2016.

14. Zhu W, Wan R, Liu F, Hu J, Huang L, Li J, Hong K. Relation of Body Mass Index With Adverse Outcomes Among Patients With Atrial Fibrillation: A Meta-Analysis and Systematic Review. J Am Heart Assoc. 2016; 5.

15. Higgins JP, Thompson SG, Deeks JJ, Altman DG. Measuring inconsistency in meta-analyses. BMJ. 2003; 327:557-560.

16. Braun OO, Bico B, Chaudhry U, Wagner H, Koul S, Tyden P, Schersten F, Jovinge S, Svensson PJ, Gustav SJ, van der Pals J. Concomitant use of warfarin and ticagrelor as an alternative to triple antithrombotic therapy after an acute coronary syndrome. Thromb Res. 2015; 135:26-30.

17. Dewilde WJ, Oirbans T, Verheugt FW, Kelder JC, De Smet BJ, Herrman JP, Adriaenssens T, Vrolix M, Heestermans AA, Vis MM, Tijsen JG, van t' Hof AW, Ten Berg JM. Use of clopidogrel with or without aspirin in patients taking oral anticoagulant therapy and undergoing percutaneous coronary intervention: an open-label, randomised, controlled trial. Lancet. 2013; 381:1107-1115.

18. Gilard M, Blanchard D, Helft G, Carrier D, Eltchaninoff H, Belle L, Finet G, Le Breton H, Boschat J. Antiplatelet therapy in patients with anticoagulants undergoing percutaneous coronary stenting (from STENTIng and oral antiCOagulants [STENTICO]). Am J Cardiol. 2009; 104:338-342. 
19. Nikolsky E, Mehran R, Dangas GD, Yu J, Parise H, Xu K, Pocock SJ, Stone GW. Outcomes of patients treated with triple antithrombotic therapy after primary percutaneous coronary intervention for ST-elevation myocardial infarction (from the Harmonizing Outcomes With Revascularization and Stents in Acute Myocardial Infarction [HORIZONSAMI] trial). Am J Cardiol. 2012; 109:831-838.

20. Pelc-Nowicka A, Bryniarski L, Mirek-Bryniarska E, Zabojszcz M. Dual antiplatelet therapy and antithrombotic treatment in patients with acute coronary syndrome--does everyday medical practice reflects current recommendations? A pilot study. Kardiol Pol. 2009; 67:1335-1341.

21. Pilgrim T, Kalesan B, Zanchin T, Pulver C, Jung S, Mattle H, Carrel T, Moschovitis A, Stortecky S, Wenaweser P, Stefanini GG, Raber L, Meier B, et al. Impact of atrial fibrillation on clinical outcomes among patients with coronary artery disease undergoing revascularisation with drug-eluting stents. Eurointervention. 2013; 8:1061-1071.

22. Povsic TJ, Roe MT, Ohman EM, Steg PG, James S, Plotnikov A, Mundl H, Welsh R, Bode C, Gibson CM. A randomized trial to compare the safety of rivaroxaban vs aspirin in addition to either clopidogrel or ticagrelor in acute coronary syndrome: The design of the GEMINI-ACS-1 phase II study. Am Heart J. 2016; 174:120-128.

23. Rubboli A, Magnavacchi P, Guastaroba P, Saia F, Vignali L, Giacometti P, Franco N, Benassi A, Varani E, Campo G, Manari A, De Palma R, Marzocchi A. Antithrombotic management and 1-year outcome of patients on oral anticoagulation undergoing coronary stent implantation (from the Registro Regionale Angioplastiche EmiliaRomagna Registry). Am J Cardiol. 2012; 109:1411-1417.

24. Sambola A, Ferreira-Gonzalez I, Angel J, Alfonso F, Maristany J, Rodriguez O, Bueno H, Lopez-Minguez JR, Zueco J, Fernandez-Aviles F, San RA, Prendergast B, Mainar V, et al. Therapeutic strategies after coronary stenting in chronically anticoagulated patients: the MUSICA study. Heart. 2009; 95:1483-1488.

25. Smith JG, Wieloch M, Koul S, Braun OO, Lumsden J, Rydell E, Ohman J, Schersten F, Svensson PJ, van der Pals J. Triple antithrombotic therapy following an acute coronary syndrome: prevalence, outcomes and prognostic utility of the HAS-BLED score. Eurointervention. 2012; 8:672-678.

26. Staudacher DL, Kaiser M, Hehrlein C, Bode C, Ahrens I. Triple Antithrombotic Therapy after Percutaneous Coronary Intervention (PCI) in Patients with Indication for Oral Anticoagulation: Data from a Single Center Registry. Plos One. 2015; 10:e140101.

27. Uchida Y, Mori F, Ogawa H, Takagi A, Hagiwara N. Impact of anticoagulant therapy with dual antiplatelet therapy on prognosis after treatment with drug-eluting coronary stents. J Cardiol. 2010; 55:362-369.

28. Zeymer U, Zahn R. [Antithrombotic therapy and atrial fibrillation. Dual or triple therapy after acute coronary syndrome and stent?]. [Article in German]. Herz. 2014; 39:814-818
29. Bernard A, Fauchier L, Pellegrin C, Clementy N, Saint EC, Banerjee A, Naudin D, Angoulvant D. Anticoagulation in patients with atrial fibrillation undergoing coronary stent implantation. Thromb Haemost. 2013; 110:560-568.

30. Enomoto Y, Iijima R, Tokue M, Ito N, Nagashima Y, Araki T, Yamazaki K, Utsunomiya M, Hori M, Itaya H, Shiba M, Hara $\mathrm{H}$, Nakamura $\mathrm{M}$, et al. Bleeding risk with triple antithrombotic therapy in patients with atrial fibrillation and drug-eluting stents. Cardiovasc Interv Ther. 2014; 29:193-199.

31. Hoshi T, Sato A, Nogami A, Gosho M, Aonuma K. Rationale and design of the SAFE-A study: SAFety and Effectiveness trial of Apixaban use in association with dual antiplatelet therapy in patients with atrial fibrillation undergoing percutaneous coronary intervention. J Cardiol. 2017; 69:648-651.

32. Rubboli A, Colletta M, Valencia J, Capecchi A, Franco N, Zanolla L, La Vecchia L, Piovaccari G, Di Pasquale G. Periprocedural management and in-hospital outcome of patients with indication for oral anticoagulation undergoing coronary artery stenting. J Interv Cardiol. 2009; 22:390-397.

33. Ruiz-Nodar JM, Marín F, Hurtado JA, Valencia J, Pinar E, Pineda J, Gimeno JR, Sogorb F, Valdés M, Lip GYH. Anticoagulant and Antiplatelet Therapy Use in 426 Patients With Atrial Fibrillation Undergoing Percutaneous Coronary Intervention and Stent Implantation. J Am Coll Cardiol. 2008; 51:818-825.

34. Maier B, Hegenbarth C, Theres H, Schoeller R, Schuehlen $\mathrm{H}$, Behrens S. Antithrombotic therapy in patients with atrial fibrillation and acute coronary syndrome in the real world: Data from the Berlin AFibACS Registry. Cardiol J. 2014; 21:465-473.

35. Vardi M, Debidda M, Bhatt DL, Mauri L, Cannon CP. Evolving antithrombotic strategies in patients with atrial fibrillation undergoing percutaneous coronary intervention: results from a survey among US cardiologists. Clin Cardiol. 2014; 37:103-107.

36. Lu W, Chen L, Wang Y, Yao Y, Fu C, Zuo P, Ma G. Rationale and design of MANJUSRI trial: a randomized, open-label, active-controlled multicenter study to evaluate the safety of combined therapy with ticagrelor and warfarin in AF subjects after PCI-eS. Contemp Clin Trials. 2015; 40:166-171.

37. Paikin JS, Wright DS, Crowther MA, Mehta SR, Eikelboom JW. Triple antithrombotic therapy in patients with atrial fibrillation and coronary artery stents. Circulation. 2010; 121:2067-2070.

38. Lamberts M, Olesen JB, Ruwald MH, Hansen CM, Karasoy D, Kristensen SL, Kober L, Torp-Pedersen C, Gislason GH, Hansen ML. Bleeding After Initiation of Multiple Antithrombotic Drugs, Including Triple Therapy, in Atrial Fibrillation Patients Following Myocardial Infarction and Coronary Intervention: A Nationwide Cohort Study. Circulation. 2012; 126:1185-1193.

39. Lamberts M, Gislason GH, Olesen JB, Kristensen SL, Schjerning Olsen A, Mikkelsen A, Christensen CB, Lip 
GYH, Køber L, Torp-Pedersen C, Hansen ML. Oral Anticoagulation and Antiplatelets in Atrial Fibrillation Patients After Myocardial Infarction and Coronary Intervention. J Am Coll Cardiol. 2013; 62:981-989.

40. Sambola A, Mutuberria M, Garcia DBB, Alonso A, Barrabes JA, Bueno H, Alfonso F, Cequier A, Zueco J, Rodriguez-Leor O, Tornos P, Garcia-Dorado D. Impact of Triple Therapy in Elderly Patients with Atrial Fibrillation Undergoing Percutaneous Coronary Intervention. Plos One. 2016; 11:e147245.

41. Ghanbari H, Nallamothu BK, Wang Y, Curtis JP. Antithrombotic therapy and outcomes after ICD implantation in patients with atrial fibrillation and coronary artery disease: an analysis from the National Cardiovascular Data Registry (NCDR)(R). J Am Heart Assoc. 2015;4.

42. Ho KW, Ivanov J, Freixa X, Overgaard CB, Osten MD, Ing D, Horlick E, Mackie K, Seidelin PH, Džavík V. Antithrombotic Therapy After Coronary Stenting in Patients With Nonvalvular Atrial Fibrillation. Can J Cardiol. 2013; 29:213-218.

43. Choi HI, Ahn JM, Kang SH, Lee PH, Kang SJ, Lee SW, Kim YH, Lee CW, Park SW, Park DW, Park SJ. Prevalence, Management, and Long-Term (6-Year) Outcomes of Atrial Fibrillation Among Patients Receiving Drug-Eluting Coronary Stents. JACC Cardiovasc Interv. 2017; 10:10751085.

44. De Vecchis R, Cantatrione C, Mazzei D. Clinical Relevance of Anticoagulation and Dual Antiplatelet Therapy to the Outcomes of Patients With Atrial Fibrillation and Recent Percutaneous Coronary Intervention With Stent. Journal of Clinical Medicine Research. 2016; 8:153-161.

45. Fan X, Zhang Y. Comparison of triple antithrombotic therapy and dual antiplatelet therapy for patients with atrial fibrillation after percutaneous coronary stenting. Pak j pharm sci. 2016; 29:1769-1773.

46. Mennuni MG, Halperin JL, Bansilal S, Schoos MM, Theodoropoulos KN, Meelu OA, Sartori S, Giacoppo D, Bernelli C, Moreno PR, Krishnan P, Baber U, Lucarelli C, et al. Balancing the Risk of Bleeding and Stroke in Patients With Atrial Fibrillation After Percutaneous Coronary Intervention (from the AVIATOR Registry). Am J Cardiol. 2015; 116:37-42.

47. Hess CN, Peterson ED, Peng SA, de Lemos JA, Fosbol EL, Thomas L, Bhatt DL, Saucedo JF, Wang TY. Use and Outcomes of Triple Therapy Among Older Patients With Acute Myocardial Infarction and Atrial Fibrillation. J Am Coll Cardiol. 2015; 66:616-627.

48. Lamberts M, Gislason GH, Lip GYH, Lassen JF, Olesen JB, Mikkelsen AP, Sorensen R, Kober L, Torp-Pedersen C, Hansen ML. Antiplatelet Therapy for Stable Coronary Artery Disease in Atrial Fibrillation Patients Taking an Oral Anticoagulant: A Nationwide Cohort Study. Circulation. 2014; 129:1577-1585.

49. Suh SY, Kang WC, Oh PC, Choi H, Moon CI, Lee K, Han SH, Ahn T, Choi IS, Shin EK. Efficacy and safety of aspirin, clopidogrel, and warfarin after coronary artery stenting in Korean patients with atrial fibrillation. Heart Vessels. 2014; 29:578-583.

50. Dabrowska M, Ochala A, Cybulski W, Tendera M. Balancing between bleeding and thromboembolism after percutaneous coronary intervention in patients with atrial fibrillation. Could triple anticoagulant therapy be a solution? Postepy Kardiol Interwencyjnej. 2013; 9:234-240.

51. Fosbol EL, Wang TY, Li S, Piccini J, Lopes RD, Mills RM, Klaskala W, Thomas L, Roe MT, Peterson ED. Warfarin use among older atrial fibrillation patients with non-STsegment elevation myocardial infarction managed with coronary stenting and dual antiplatelet therapy. Am Heart J. 2013; 166:864-870.

52. Maegdefessel L, Schlitt A, Faerber J, Bond SP, Messow CM, Buerke M, Raaz U, Werdan K, Muenzel T, Weiss C. Anticoagulant and/or antiplatelet treatment in patients with atrial fibrillation after percutaneous coronary intervention. A single-center experience. Med Klin (Munich). 2008; 103:628-632.

53. Lip GY, Huber K, Andreotti F, Arnesen H, Airaksinen JK, Cuisset T, Kirchhof P, Marin F. Antithrombotic management of atrial fibrillation patients presenting with acute coronary syndrome and/or undergoing coronary stenting: executive summary--a Consensus Document of the European Society of Cardiology Working Group on Thrombosis, endorsed by the European Heart Rhythm Association (EHRA) and the European Association of Percutaneous Cardiovascular Interventions (EAPCI). Eur Heart J. 2010; 31:1311-1318.

54. Lip GY, Windecker S, Huber K, Kirchhof P, Marin F, Ten BJ, Haeusler KG, Boriani G, Capodanno D, Gilard M, Zeymer U, Lane D, Storey RF, et al. Management of antithrombotic therapy in atrial fibrillation patients presenting with acute coronary syndrome and/or undergoing percutaneous coronary or valve interventions: a joint consensus document of the European Society of Cardiology Working Group on Thrombosis, European Heart Rhythm Association (EHRA), European Association of Percutaneous Cardiovascular Interventions (EAPCI) and European Association of Acute Cardiac Care (ACCA) endorsed by the Heart Rhythm Society (HRS) and AsiaPacific Heart Rhythm Society (APHRS). Eur Heart J. 2014; 35:3155-3179.

55. Liu J, Fan M, Zhao J, Zhao B, Zhang C, Liu C, Dong Y. Efficacy and safety of antithrombotic regimens after coronary intervention in patients on oral anticoagulation: Traditional and Bayesian meta-analysis of clinical trials. Int J Cardiol. 2016; 205:89-96.

56. Washam JB, Dolor RJ, Jones WS, Halim SA, Hasselblad V, Mayer SB, Heidenfelder BL, Melloni C. Dual antiplatelet therapy with or without oral anticoagulation in the postdischarge management of acute coronary syndrome patients with an indication for long term anticoagulation: a systematic review. J Thromb Thrombolysis. 2014; 38:285-298.

57. Olson KL, Delate T, Johnson SG, Wilson ED, Witt DM. Incidence of hemorrhage among anticoagulated patients 
receiving antiplatelet therapy after percutaneous coronary intervention. J Thromb Thrombolysis. 2010; 29:316-321.

58. Hughes M, Lip GY. Risk factors for anticoagulation-related bleeding complications in patients with atrial fibrillation: a systematic review. QJM. 2007; 100:599-607.

59. Rossini R, Musumeci G, Lettieri C, Molfese M, Mihalcsik L, Mantovani P, Sirbu V, Bass TA, Della RF, Gavazzi A, Angiolillo DJ. Long-term outcomes in patients undergoing coronary stenting on dual oral antiplatelet treatment requiring oral anticoagulant therapy. Am J Cardiol. 2008; 102:1618-1623.

60. D'Ascenzo F, Taha S, Moretti C, Omede P, Grossomarra W, Persson J, Lamberts M, Dewilde W, Rubboli A, Fernandez S, Cerrato E, Meynet I, Ballocca F, et al. Metaanalysis of randomized controlled trials and adjusted observational results of use of clopidogrel, aspirin, and oral anticoagulants in patients undergoing percutaneous coronary intervention. Am J Cardiol. 2015; 115:1185-1193.

61. Agarwal N, Jain A, Mahmoud AN, Bishnoi R, Golwala H, Karimi A, Mojadidi MK, Garg J, Gupta T, Patel NK, Wayangankar S, Anderson RD. Safety and Efficacy of Dual Versus Triple Antithrombotic Therapy in Patients Undergoing Percutaneous Coronary Intervention. Am J Med. 2017. [Epub ahead of print].

62. Roy P, Bonello L, Torguson R, de Labriolle A, Lemesle G, Slottow TL, Steinberg DH, Kaneshige K, Xue Z, Satler LF, Kent KM, Suddath WO, Pichard AD, et al. Impact of "nuisance" bleeding on clopidogrel compliance in patients undergoing intracoronary drug-eluting stent implantation. Am J Cardiol. 2008; 102:1614-1617.

63. January CT, Wann LS, Alpert JS, Calkins H, Cigarroa JE, Cleveland JJ, Conti JB, Ellinor PT, Ezekowitz MD, Field ME, Murray KT, Sacco RL, Stevenson WG, et al. 2014 AHA/ACC/HRS guideline for the management of patients with atrial fibrillation: a report of the American College of Cardiology/American Heart Association Task Force on Practice Guidelines and the Heart Rhythm Society. J Am Coll Cardiol. 2014; 64:e1-e76.

64. Kirchhof P, Benussi S, Kotecha D, Ahlsson A, Atar D, Casadei B, Castella M, Diener HC, Heidbuchel H, Hendriks J, Hindricks G, Manolis AS, Oldgren J, et al. 2016 ESC Guidelines for the management of atrial fibrillation developed in collaboration with EACTS. Eur Heart J. 2016; 37:2893-2962.
65. Patel MR, Mahaffey KW, Garg J, Pan G, Singer DE, Hacke W, Breithardt G, Halperin JL, Hankey GJ, Piccini JP, Becker RC, Nessel CC, Paolini JF, et al. Rivaroxaban versus warfarin in nonvalvular atrial fibrillation. N Engl J Med. 2011; 365:883-891.

66. Mega JL, Braunwald E, Wiviott SD, Bassand JP, Bhatt DL, Bode C, Burton P, Cohen M, Cook-Bruns N, Fox KA, Goto S, Murphy SA, Plotnikov AN, et al. Rivaroxaban in patients with a recent acute coronary syndrome. N Engl J Med. 2012; 366:9-19.

67. Gibson CM, Mehran R, Bode C, Halperin J, Verheugt FW, Wildgoose P, Birmingham M, Ianus J, Burton P, van Eickels M, Korjian S, Daaboul Y, Lip GY, et al. Prevention of Bleeding in Patients with Atrial Fibrillation Undergoing PCI. N Engl J Med. 2016; 375:2423-2434.

68. Gao F, Shen H, Wang ZJ, Yang SW, Liu XL, Zhou YJ. Rationale and design of the RT-AF study: Combination of rivaroxaban and ticagrelor in patients with atrial fibrillation and coronary artery disease undergoing percutaneous coronary intervention. Contemp Clin Trials. 2015; 43:129132.

69. Cannon CP, Gropper S, Bhatt DL, Ellis SG, Kimura T, Lip GY, Steg PG, Ten BJ, Manassie J, Kreuzer J, Blatchford J, Massaro JM, Brueckmann M, et al. Design and Rationale of the RE-DUAL PCI Trial: A Prospective, Randomized, Phase $3 \mathrm{~b}$ Study Comparing the Safety and Efficacy of Dual Antithrombotic Therapy With Dabigatran Etexilate Versus Warfarin Triple Therapy in Patients With Nonvalvular Atrial Fibrillation Who Have Undergone Percutaneous Coronary Intervention With Stenting. Clin Cardiol. 2016; 39:555-564.

70. Bristol-Myers Squibb. A Study of Apixaban in Patients With Atrial Fibrillation, Not Caused by a Heart Valve Problem, Who Are at Risk for Thrombosis (Blood Clots) Due to Having Had a Recent Coronary Event, Such as a Heart Attack or a Procedure to Open the Vessels of the Heart. Available at: https://www.clinicaltrials.gov/ct2/show/ NCT02415400. Accessed August 7, 2017. 